\title{
Serum lipid-improving effect of soyabean $\beta$-conglycinin in hyperlipidaemic menopausal women
}

\author{
Defu $\mathrm{Ma}^{1}$, Kyoko Taku ${ }^{2 *}$, Yumei Zhang ${ }^{3 *}$, Meng $\mathrm{Jia}^{3}$, Yang Wang ${ }^{3}$ and Peiyu Wang ${ }^{1}$ \\ ${ }^{1}$ Department of Social Medicine and Health Education, School of Public Health, Peking University Health Science Center, \\ Beijing 100191, People's Republic of China \\ ${ }^{2}$ Center for International Collaboration and Partnership, National Institute of Health and Nutrition, 1-23-1 Toyama, \\ Shinjuku-ku, Tokyo 162-8636, Japan \\ ${ }^{3}$ Department of Nutrition and Food Hygiene, School of Public Health, Peking University Health Science Center, \\ 38 Xueyuan Road, Haidian District, Beijing 100191, People's Republic of China
}

(Submitted 1 October 2012 - Final revision received 22 February 2013 - Accepted 5 March 2013 - First published online 8 April 2013)

\begin{abstract}
To evaluate the effect of treatment with $\beta$-conglycinin, a major soyabean protein, on blood lipids in menopausal women, we recruited 100 hyperlipidaemic women aged 40-60 years old. Participants were randomly allocated to three groups: placebo group ( $n$ 34, four casein tablets/d); low dose group ( $n$ 33, four tablets containing $2.3 \mathrm{~g} \beta$-conglycinin/d); high-dose group ( $n$ 33, eight tablets containing $4.6 \mathrm{~g}$ $\beta$-conglycinin/d). The mean serum TAG concentration was significantly reduced after 6 and 12 weeks of $\beta$-conglycinin intervention by $0.44(\mathrm{sD} 0.20$ ) and 0.78 (SD 1.03$) \mathrm{mmol} / \mathrm{l}$ in the low-dose group, and by 0.46 (SD 0.17 ) and 1.25 (SD 1.06 ) mmol/1 in the high-dose group, respectively. One-way ANOVA revealed that serum TAG concentrations in the low-dose and high-dose groups were significantly lowered compared with the placebo group at weeks 6 and $12(P<0 \cdot 05)$. The low dose and high dose consumptions of $\beta$-conglycinin significantly decreased the LDL-cholesterol concentration by 0.46 (SD 0.72 ) and 0.52 (SD 0.97 ) mmol/1 at week 12 , respectively $(P<0.05)$. Compared with the changes from baseline in the placebo group, apoB and NEFA were significantly lowered in both the low-dose and high-dose $\beta$-conglycinin groups $(P<0 \cdot 05)$. In conclusion, the results suggest that $\beta$-conglycinin intake significantly decreases serum TAG and LDL-cholesterol levels.
\end{abstract}

Key words: $\beta$-Conglycinin: Soyabeans: Menopausal women: Serum lipids: Hypertriacylglycerolaemia

Soyabeans, the most popular type of beans consumed worldwide, contain a type of protein that is known to have beneficial effects on human health, such as the ability to lower cholesterol and TAG levels ${ }^{(1)}$. Studies on the cholesterol- and TAG-lowering ability of soya protein isolate have indicated that the effects are principally exerted by proteins in themselves, although the isoflavone content also contributes to these effects ${ }^{(2)}$. In 1999, the US Food and Drug Administration $^{(3)}$ authorised the health claim that a daily ingestion of $25 \mathrm{~g}$ soyabean protein isolate reduces the risk of heart disease. However, earlier research indicating that soya protein, when compared with other proteins, has clinically important favourable effects on LDL-cholesterol (LDL-C) and other heart disease risk factors has not been confirmed by many studies reported during the past 10 years $^{(4)}$. Soya protein is not a single protein, but is composed of several proteins with different characteristics. The major storage proteins of soyabeans are $\beta$-conglycinin and glycinin. Most of the past studies were performed with either the $\beta$-conglycinin or glycinin fraction to identify the functional protein moieties in soya protein isolate ${ }^{(2,5)}$.

Recent in vivo studies have revealed that $\beta$-conglycinin, which is a major component of the reserve protein fraction and accounts for $16 \cdot 8-20.9 \%$ of soya protein, has both anti-arteriosclerotic and serum TAG-reducing effects ${ }^{(6)}$. A study by Sirtori et al. ${ }^{(7)}$ showed that $\beta$-conglycinin consumption reduced plasma cholesterol concentration by $35 \%$ in rats. A $\beta$-conglycinin-rich diet, but not a casein-rich or glycinin-rich diet, resulted in significant decreases in serum TAG, glucose and insulin levels with a decrease in body weights in normal mice (ICR) and genetically obese mice (KK-Ay) under energy-restricted conditions ${ }^{(8)}$. In a human randomised, double-blind, placebo-controlled study, a 12-week consumption of $5 \mathrm{~g}$ soyabean $\beta$-conglycinin per $\mathrm{d}$ significantly reduced serum TAG concentrations from $2 \cdot 65$ to $2 \cdot 29 \mathrm{mmol} / 1$,

Abbreviations: HDL-C, HDL-cholesterol; LDL-C, LDL-cholesterol.

*Corresponding authors: K. Taku, fax +8133202 3278, email takuk@nih.go.jps; Y. Zhang, fax +86 1062059551 , email madefu@bjmu.edu.cn and zhangyumei111@gmail.com 
whereas the consumption of $5 \mathrm{~g}$ casein did not show such an effect $^{(9)}$. In addition, its effects on serum lipids were examined in subjects with mild hypertriacylglycerolaemia in a randomised controlled study ${ }^{(10)}$.

However, $\beta$-conglycinin has rarely been studied clinically in menopausal women. Epidemiological investigations have found that the levels of serum LDL-C and TAG were supposed to increase while HDL-cholesterol (HDL-C) was supposed to decrease during the menopausal period, which increased the risk of cardiovascular disease in menopausal women. Therefore, we performed a 12-week placebo-controlled, randomised, parallel study to examine the health effect of soyabean $\beta$-conglycinin on serum lipids in hyperlipidaemic menopausal women.

\section{Materials and methods}

\section{Subjects}

Perimenopausal women aged 40-66 years who registered at community hospitals in two Beijing universities were recruited. According to the evaluation criteria of the effectiveness of health food on serum lipid for the Chinese population (Standard of Health Food Test and Asses (2003), Ministry of Health of China), female subjects with total cholesterol $\geq 6.22 \mathrm{mmol} / 1(2400 \mathrm{mg} / \mathrm{l})$ or TAG $\geq 1.80 \mathrm{mmol} / 1$ were included. Individuals with chronic diseases, such as diabetes and hypertension, or soyabean allergies and those taking hypolipidaemic drugs were excluded from the study. In total, 100 volunteers were selected within $7 \mathrm{~d}$ before the initiation of treatment with $\beta$-conglycinin. A controller, who was blinded to the present study, randomly assigned the selected subjects to three groups (low-dose group, high-dose group and placebo group) using a list of random numbers, and then confirmed that there were no significant differences in serum lipids, age or BMI among the three groups.

The present study was conducted according to the guidelines laid down in the Declaration of Helsinki, and all procedures involving human subjects were approved by the Peking University Biomedical Ethics Committee. Written informed consent was obtained from all subjects. At the beginning of the study, all volunteers accepted a training for $24 \mathrm{~h}$ dietary records and guidelines for drawing of blood samples.

\section{Experimental food}

Soyabean $\beta$-conglycinin products obtained from Fuji Oil Company (Osaka, Japan) were a functional food with marketing approval. The test foods contained $2.3 \mathrm{~g} \beta$-conglycinin, $0.2 \mathrm{~g}$ fat, $3 \cdot 1 \mathrm{~g}$ carbohydrate and $45 \mathrm{mg} \mathrm{Na}$ in every four tablets. Placebo tablets were prepared by substituting maize starch with $\beta$-conglycinin, with energy being adjusted to be equivalent to that of the test foods.

\section{Study design}

The present study had a 14-week, placebo-controlled, randomised design, consisting of a 2 -week run-in period (no treatment) and a 12 -week treatment period. During the treatment period, subjects in the low-dose and placebo groups took four tablets daily of the test and placebo tablets, respectively, and those in the high-dose group took eight test tablets daily. The four and eight test tablets contained $2 \cdot 3$ and $4.6 \mathrm{~g} \beta$-conglycinin, respectively. Throughout the treatment period, the researchers investigated the $24 \mathrm{~h}$ dietary intake (including beverages) for three consecutive days and physical activity by a questionnaire before drawing the blood samples. Additionally, subjects were asked not to change their usual activities of daily living such as eating habits, smoking, exercise, etc.

\section{Measurements}

Blood samples were collected from each participant at 09.00 hours in the morning and drawn three times in total at weeks 0,6 and 12 of the treatment period. Subjects were required to fast from 20.00 hours the previous night and alcohol was prohibited in the dinner meal. Serum TAG and total cholesterol were measured by the glycerol phosphate oxidase-peroxidase (PAP) method. LDL-C and HDL-C were measured directly. NEFA were measured by a free fatty acid quantification kit (Biovision). ApoAI and apoB concentrations were measured by a turbidimetric immunoassay. In addition, serum triiodothyronine and thyroxine were detected by competitive immunoassay methods. All these tests were conducted at SRL Company Limited. For quality control, the standard sample of each kit was used for calibration.

\section{Statistical analysis}

Data are presented as means and standard deviations. One-way ANOVA was performed for assessing the whole group for differences among the three times (with repeated measures) or the three groups. For specific time/dose differences, simultaneous difference testing among the three groups across the different time points was carried out using a univariate splitplot approach with post hoc repeated-measures ANOVA. SPSS (version 16; SPSS, Inc.) was used for all statistical analyses, with a two-sided $5 \%$ significance level.

\section{Results}

\section{Subjects and energy intake}

A total of ten ( $n$ 3, low-dose group; $n$ 3, high-dose group; $n 4$, control group) subjects dropped out for personal reasons during the study period, resulting in ninety subjects who were eventually analysed in the present study. Baseline characteristics of the participants in the three groups are summarised in Table 1. At the beginning of the study, age, weight, BMI and serum lipids (total cholesterol, LDL-C, TAG and HDL-C) were similar among the three groups. Throughout the study, food intake, sleep, bowel habit and mental state of the ninety participants remained stable. There was no report of side effects during the study. There were no significant differences on the intake of dietary protein, carbohydrate, fat and total energy among the three groups throughout the study period (Table 2). 
Table 1. Baseline characteristics of the participants in the study

(Mean values and standard deviations)

\begin{tabular}{|c|c|c|c|c|c|c|}
\hline \multirow[t]{2}{*}{ Groups... } & \multicolumn{2}{|c|}{ Placebo } & \multicolumn{2}{|c|}{ Low dose } & \multicolumn{2}{|c|}{ High dose } \\
\hline & Mean & SD & Mean & SD & Mean & SD \\
\hline$n$ & \multicolumn{2}{|c|}{30} & \multicolumn{2}{|c|}{30} & \multicolumn{2}{|c|}{30} \\
\hline Age (years) & $54 \cdot 4$ & $4 \cdot 3$ & $52 \cdot 7$ & $4 \cdot 6$ & $53 \cdot 1$ & $4 \cdot 7$ \\
\hline Weight (kg) & $62 \cdot 8$ & $4 \cdot 1$ & 64.5 & $5 \cdot 1$ & $63 \cdot 2$ & 3.4 \\
\hline BMI $\left(\mathrm{kg} / \mathrm{m}^{2}\right)$ & $23 \cdot 8$ & 1.4 & 24.5 & $2 \cdot 0$ & $24 \cdot 4$ & 1.5 \\
\hline TAG $(\mathrm{mmol} / \mathrm{l})$ & 3.79 & $1 \cdot 32$ & $3 \cdot 20$ & 0.74 & $3 \cdot 23$ & 1.40 \\
\hline NEFA (mEq/l) & 0.60 & 0.07 & 0.59 & 0.07 & 0.60 & 0.05 \\
\hline Free T3 (ng/l) & $5 \cdot 75$ & 0.47 & $5 \cdot 46$ & 0.53 & $5 \cdot 62$ & 0.56 \\
\hline Free T4 (ng/l) & $15 \cdot 81$ & 0.85 & $16 \cdot 23$ & 0.89 & $15 \cdot 89$ & 0.91 \\
\hline Total cholesterol $(\mathrm{mmol} / \mathrm{l})$ & $6 \cdot 43$ & 0.81 & 6.53 & 0.73 & $6 \cdot 43$ & 1.06 \\
\hline LDL-cholesterol (mmol/l) & $3 \cdot 68$ & 0.68 & 3.91 & 0.58 & 3.91 & 0.95 \\
\hline HDL-cholesterol (mmol/l) & $1 \cdot 18$ & 0.26 & $1 \cdot 20$ & 0.36 & $1 \cdot 21$ & 0.29 \\
\hline ApoA1 $(g / l)$ & 1.54 & 0.09 & 1.52 & $0 \cdot 15$ & 1.50 & $0 \cdot 14$ \\
\hline ApoB $(g / l)$ & 1.09 & 0.09 & $1 \cdot 16$ & 0.10 & $1 \cdot 13$ & $0 \cdot 13$ \\
\hline
\end{tabular}

T3, triiodothyronine; T4, thyroxine.

\section{Serum lipids}

The measurements of serum lipids are shown in Table 3. The mean serum TAG concentration in the low-dose group was significantly reduced after 6 and 12 weeks of $\beta$-conglycinin consumption by $0.44(\mathrm{SD} \quad 0.20)$ and 0.78 (SD 1.03 ) $\mathrm{mmol} / \mathrm{l}$, respectively $(P<0.05)$. The high dose consumption of $\beta$-conglycinin also significantly decreased the serum TAG concentration after the 6- and 12-week interventions. One-way ANOVA showed that serum TAG concentrations in the lowdose and high-dose groups were significantly lower than those in the placebo group at weeks 6 and 12. The general linear model for repeated measures showed that the change trend in the low-dose and high-dose groups was significantly different from that in the placebo group $(P<0 \cdot 05)$. The placebo group did not exhibit significant differences in serum TAG during the test period. For NEFA, a comparison of the intra-group variation from the baseline value revealed significant differences in the test groups at weeks 6 and $12(P<0 \cdot 05)$. Oneway ANOVA revealed that NEFA in the low-dose and high-dose groups were significantly lowered compared with the placebo group at week 12 . The $\beta$-conglycinin intervention had no effect on free triiodothyronine and free thyroxine (Table 3 ).

For lipoprotein cholesterol, compared with the baseline value, the mean LDL-C concentration in the low-dose and high-dose groups was decreased by 0.46 (SD 0.72 ) and 0.52 (sD 0.97) $\mathrm{mmol} / \mathrm{l}$ after 12 weeks, respectively. One-way ANOVA revealed that serum LDL-C concentrations in the low-dose and high-dose groups were significantly lowered than that in the placebo group at week $12(P<0 \cdot 05)$. The $\beta$-conglycinin intervention had no effect on total cholesterol and HDL-C (Table 3).

The mean apoB concentration in the low-dose group was significantly decreased after the 6- and 12-week interventions. The high-dose group showed a similar apoB-reducing

Table 2. Main nutrient intake for $3 \mathrm{~d}$ before blood collection and changes in weight from the study subjects (Mean values and standard deviations)

\begin{tabular}{|c|c|c|c|c|c|c|c|}
\hline \multirow[b]{2}{*}{ Groups } & \multirow[b]{2}{*}{$n$} & \multicolumn{2}{|c|}{0 weeks } & \multicolumn{2}{|c|}{6 weeks } & \multicolumn{2}{|c|}{12 weeks } \\
\hline & & Mean & SD & Mean & SD & Mean & SD \\
\hline \multicolumn{8}{|l|}{ Weight (kg) } \\
\hline Placebo & 30 & $62 \cdot 8$ & $4 \cdot 3$ & & & $63 \cdot 6$ & 4.3 \\
\hline Low dose & 30 & 64.5 & $5 \cdot 1$ & & & $64 \cdot 6$ & $5 \cdot 2$ \\
\hline High dose & 30 & $63 \cdot 2$ & $3 \cdot 4$ & & & 63.4 & 3.5 \\
\hline \multicolumn{8}{|c|}{ Energy intake $(\mathrm{kJ} / \mathrm{d})$} \\
\hline Placebo & 30 & 8372 & 1844 & 7611 & 1769 & 8019 & 4504 \\
\hline Low dose & 30 & 8519 & 2446 & 7816 & 1526 & 8013 & 3061 \\
\hline High dose & 30 & 8021 & 1982 & 7243 & 1359 & 7929 & 3137 \\
\hline \multicolumn{8}{|c|}{ Protein intake $(\mathrm{g} / \mathrm{d})$} \\
\hline Placebo & 30 & 71.0 & $27 \cdot 8$ & 67.4 & $25 \cdot 5$ & $85 \cdot 4$ & $82 \cdot 6$ \\
\hline Low dose & 30 & $73 \cdot 7$ & $19 \cdot 9$ & 74.9 & $20 \cdot 7$ & $80 \cdot 4$ & $40 \cdot 3$ \\
\hline High dose & 30 & $78 \cdot 3$ & $28 \cdot 6$ & $65 \cdot 7$ & $22 \cdot 9$ & $75 \cdot 0$ & $26 \cdot 5$ \\
\hline \multicolumn{8}{|c|}{ Fat intake $(\mathrm{g} / \mathrm{d})$} \\
\hline Placebo & 30 & $57 \cdot 2$ & $29 \cdot 6$ & $51 \cdot 0$ & $20 \cdot 3$ & $53 \cdot 1$ & $40 \cdot 7$ \\
\hline Low dose & 30 & $55 \cdot 1$ & $29 \cdot 0$ & $55 \cdot 7$ & $21 \cdot 1$ & 60.5 & 37.4 \\
\hline High dose & 30 & $58 \cdot 6$ & 277 & $51 \cdot 0$ & $19 \cdot 2$ & $56 \cdot 7$ & $30 \cdot 3$ \\
\hline \multicolumn{8}{|c|}{ Carbohydrate intake $(\mathrm{g} / \mathrm{d})$} \\
\hline Placebo & 30 & 207.0 & 55.8 & $217 \cdot 8$ & $56 \cdot 3$ & $217 \cdot 6$ & $113 \cdot 1$ \\
\hline Low dose & 30 & $214 \cdot 3$ & $69 \cdot 0$ & $213 \cdot 7$ & $45 \cdot 1$ & $216 \cdot 4$ & $112 \cdot 8$ \\
\hline High dose & 30 & 195.9 & $58 \cdot 0$ & $195 \cdot 1$ & $49 \cdot 3$ & 223.4 & 145.4 \\
\hline
\end{tabular}


Table 3. Effect of $\beta$-conglycinin on serum lipid concentrations and thyroid hormones

(Mean values and standard deviations)

\begin{tabular}{|c|c|c|c|c|c|c|c|c|c|c|c|}
\hline \multirow[b]{2}{*}{ Groups } & \multirow[b]{2}{*}{$n$} & \multicolumn{2}{|c|}{0 weeks } & \multicolumn{2}{|c|}{6 weeks } & \multicolumn{2}{|c|}{12 weeks } & \multicolumn{2}{|c|}{$\Delta 6$ weeks } & \multicolumn{2}{|c|}{$\Delta 12$ weeks } \\
\hline & & Mean & SD & Mean & SD & Mean & SD & Mean & SD & Mean & SD \\
\hline \multicolumn{12}{|l|}{ TAG (mmol/l) } \\
\hline Placebo & 30 & 3.79 & 1.32 & 3.88 & 0.95 & 3.84 & 1.26 & 0.09 & 0.71 & 0.05 & 0.73 \\
\hline Low dose & 30 & $3 \cdot 20$ & 0.74 & $2 \cdot 76^{\star} \dagger$ & 0.77 & $2 \cdot 41^{\star} \dagger$ & 0.78 & $-0.44 \dagger$ & 0.20 & $-0.78 \dagger$ & 1.03 \\
\hline High dose & 30 & $3 \cdot 23$ & 1.40 & $2 \cdot 77^{*} \dagger$ & 1.35 & $1.99^{*} \dagger$ & 0.85 & $-0.46 \dagger$ & 0.17 & $-1.25 \dagger$ & 1.06 \\
\hline \multicolumn{12}{|l|}{ NEFA (mEq/l) } \\
\hline Placebo & 30 & 0.60 & 0.07 & $0.52^{*}$ & 0.04 & $0.54^{\star}$ & 0.05 & -0.08 & 0.06 & -0.06 & 0.09 \\
\hline Low dose & 30 & 0.59 & 0.07 & $0.54^{\star}$ & 0.04 & $0.47^{\star} \dagger$ & 0.03 & -0.06 & 0.09 & $-0.12 \dagger$ & 0.08 \\
\hline High dose & 30 & 0.60 & 0.05 & $0.51^{*}$ & 0.05 & $0.47^{\star} \dagger$ & 0.03 & -0.09 & 0.07 & $-0.12 \dagger$ & 0.06 \\
\hline \multicolumn{12}{|l|}{ Free T3 (ng/l) } \\
\hline Placebo & 30 & $5 \cdot 75$ & 0.47 & $5 \cdot 15^{\star}$ & 0.66 & $5 \cdot 23^{*}$ & 1.10 & -0.61 & 0.78 & -0.53 & 1.32 \\
\hline Low dose & 30 & 5.46 & 0.53 & $5 \cdot 01^{*}$ & 0.66 & 5.40 & 1.21 & -0.44 & 0.89 & -0.06 & 1.25 \\
\hline High dose & 30 & $5 \cdot 62$ & 0.56 & $5 \cdot 14^{*}$ & 0.66 & 5.44 & 1.34 & -0.48 & 0.92 & -0.18 & 1.55 \\
\hline \multicolumn{12}{|l|}{ Free T4 (ng/l) } \\
\hline Placebo & 30 & $15 \cdot 81$ & 0.85 & $15 \cdot 30$ & 1.73 & $16 \cdot 77$ & 4.39 & -0.51 & 1.9 & 0.96 & 4.55 \\
\hline Low dose & 30 & $16 \cdot 23$ & 0.89 & $16 \cdot 16^{*}$ & 1.74 & $16 \cdot 88$ & 4.42 & -0.07 & 1.69 & 0.65 & 4.51 \\
\hline High dose & 30 & $15 \cdot 89$ & 0.91 & $15 \cdot 72$ & 1.55 & $15 \cdot 96$ & 2.03 & -0.16 & 1.90 & 0.07 & $2 \cdot 16$ \\
\hline \multicolumn{12}{|c|}{ Total cholesterol $(\mathrm{mmol} / \mathrm{l})$} \\
\hline Placebo & 30 & 6.43 & 0.81 & 6.04 & 0.87 & $6 \cdot 72^{*}$ & 0.77 & -0.39 & 1.08 & 0.29 & 0.46 \\
\hline Low dose & 30 & 6.53 & 0.73 & $5 \cdot 79^{\star}$ & 0.88 & $6 \cdot 36$ & 0.82 & -0.74 & $1 \cdot 24$ & $-0.17 \dagger$ & 0.74 \\
\hline High dose & 30 & 6.43 & 1.06 & $6 \cdot 10$ & 0.82 & $6 \cdot 22$ & 0.97 & -0.32 & 0.99 & $-0.21 \dagger$ & 1.09 \\
\hline \multicolumn{12}{|c|}{ LDL-cholesterol $(\mathrm{mmol} / \mathrm{l})$} \\
\hline Placebo & 30 & 3.68 & 0.69 & 3.73 & 0.39 & 3.87 & 0.86 & 0.05 & 0.82 & 0.20 & 0.59 \\
\hline Low dose & 30 & 3.91 & 0.58 & $3.44^{*}$ & 0.48 & $3.45^{\star} \dagger$ & 0.56 & $-0.47 \dagger$ & 0.73 & $-0.46 \dagger$ & 0.72 \\
\hline High dose & 30 & 3.91 & 0.95 & 3.64 & 0.42 & $3 \cdot 39^{*} \dagger$ & 0.58 & -0.27 & 1.06 & $-0.52 \dagger$ & 0.97 \\
\hline \multicolumn{12}{|c|}{ HDL-cholesterol (mmol/l) } \\
\hline Placebo & 30 & $1 \cdot 17$ & 0.26 & $1.37^{\star}$ & 0.22 & 1.22 & 0.28 & 0.19 & 0.33 & 0.04 & 0.30 \\
\hline Low dose & 30 & $1 \cdot 20$ & 0.36 & 1.15 & 0.21 & $1 \cdot 16$ & 0.14 & $-0.05 t$ & 0.39 & -0.04 & 0.36 \\
\hline High dose & 30 & 1.21 & 0.29 & 1.29 & 0.25 & 1.23 & 0.26 & 0.08 & 0.40 & 0.03 & 0.33 \\
\hline \multicolumn{12}{|l|}{ ApoA1 (g/l) } \\
\hline Placebo & 30 & 1.54 & 0.09 & $1 \cdot 26^{*}$ & 0.18 & $1.69^{*}$ & 0.21 & -0.28 & 0.20 & 0.15 & 0.23 \\
\hline Low dose & 30 & 1.52 & 0.15 & $1 \cdot 34^{\star}$ & 0.18 & $1.68^{*}$ & 0.24 & -0.18 & 0.21 & 0.16 & 0.30 \\
\hline High dose & 30 & 1.50 & 0.14 & $1.27^{\star}$ & 0.17 & $1 \cdot 61^{*}$ & 0.19 & -0.23 & 0.21 & 0.11 & 0.27 \\
\hline \multicolumn{12}{|l|}{ ApoB (g/l) } \\
\hline Placebo & 30 & 1.09 & 0.09 & $1 \cdot 11$ & 0.07 & $1 \cdot 15^{\star}$ & 0.13 & 0.02 & 0.11 & 0.07 & 0.16 \\
\hline Low dose & 30 & $1 \cdot 16$ & $0 \cdot 10$ & $1.04^{\star}$ & 0.10 & $1.04^{*} \dagger$ & 0.22 & $-0.11 \dagger$ & 0.14 & $-0.12 \dagger$ & 0.22 \\
\hline High dose & 30 & $1 \cdot 13$ & 0.13 & $0.99^{*}$ & 0.13 & $0.98^{*} \dagger$ & 0.13 & $-0.13 t$ & 0.18 & $-0.15 t$ & 0.21 \\
\hline
\end{tabular}

T3, triiodothyronine; T4, thyroxine.

* Mean values were significantly different from those of baseline $(P<0.05$; paired $t$ test $)$

† Mean values were significantly different from those of placebo $(P<0.05)$.

effect $(P<0.05)$. One-way ANOVA showed that serum apoB concentrations in the low-dose and high-dose groups were significantly lower compared with the placebo group at weeks 6 and 12. The general linear model for repeated measures showed that the change trend of apoB in the lowdose and high-dose groups was significantly different from that in the placebo group $(P<0 \cdot 05)$. The $\beta$-conglycinin intervention had no effect on apoAI (Table 3 ).

\section{Discussion}

The present study was the first to evaluate the effect of the soyabean $\beta$-conglycinin intervention on serum lipid metabolism in menopausal women, a population prone to develop dyslipidaemia. In the present study, we found that soyabean $\beta$-conglycinin interventions of 2.3 and $4.6 \mathrm{~g} / \mathrm{d}$ significantly decreased the serum levels of TAG, LDL-C, NEFA and apoB at weeks 6 and 12 .

Several animal studies have reported the serum TAGreducing effects of soyabean $\beta$-conglycinin. The results of the study performed by Fukui et al. ${ }^{(11)}$ are concurrent with experimental work in rats in which $\beta$-conglycinin reduction of serum TAG was concomitant to the suppression of hepatic fatty acid synthesis and the promotion of fatty acid oxidation. In addition, some human interventional studies have proved the serum lipid-improving effects of $\beta$-conglycinin. In a placebo-controlled, randomised, double-blind study, a $2 \cdot 3 \mathrm{~g}$ $\beta$-conglycinin intervention for 12 weeks significantly decreased the level of TAG in subjects with serum TAG levels of $1.70-3.39 \mathrm{mmol} / \mathrm{l}^{(12)}$. In another study, daily consumption of $5 \mathrm{~g} \beta$-conglycinin significantly reduced the TAG concentration and visceral fat after 12 weeks, which suggested that $\beta$-conglycinin is an effective food ingredient useful to reduce high serum TAG and prevent obesity ${ }^{(9)}$. Similar to previous studies, we found that a low-dose $(2.3 \mathrm{~g} / \mathrm{d})$ and a high-dose $(4.6 \mathrm{~g} / \mathrm{d})$ $\beta$-conglycinin intervention significantly decreased TAG by 21.7 and $34.5 \%$ at week 12 , respectively.

Many studies have confirmed that soyabean protein can reduce the blood LDL-C level from 7.9 to $10 \cdot 3 \%{ }^{(13)}$. In the present study, we found that $\beta$-conglycinin consumption of 
2.3 and $4.6 \mathrm{~g} / \mathrm{d}$ for 12 weeks significantly decreased LDL-C concentrations by $10 \cdot 23$ and $13 \cdot 3 \%$, respectively. Mochizuki et al. ${ }^{(14)}$ used high-purity $7 \mathrm{~S}$-soyabean peptides isolated from $7 \mathrm{~S}$ soyabean $\beta$-conglycinin in a HepG2 cell assay, and found that $7 \mathrm{~S}$ soyabean $\beta$-conglycinin could significantly inhibit the secretion of apoB-100, regulate sterol regulatory elementbinding protein 2 expression and inhibit endogenous synthesis of cholesterol. We also found a significant apoB-reducing effect in the $\beta$-conglycinin interventional groups at weeks 6 and 12. In human subjects, the estimated average intake of $\beta$-conglycinin is low. The mean intake of beans (mostly soyabeans) and related foods in Japanese and Chinese populations over 1 year of age was $56.0 \mathrm{~g} / \mathrm{d}$, and protein intake was $4.8 \mathrm{~g} / \mathrm{d}^{(15)}$. Because about $20 \%$ of the soya protein consumed was $\beta$-conglycinin, on average, about $1 \mathrm{~g} \beta$-conglycinin was consumed per $d$. The present study suggest that consumption of $2 \cdot 3 \mathrm{~g} \beta$-conglycinin for 6 weeks was enough to show a significant serum lipid-improving effect in menopausal women. Therefore, in humans, additional supplementation of $2.3 \mathrm{~g} \beta$-conglycinin is necessary to improve serum lipids.

The details of the mechanism underlying the decrease in serum lipids caused by soyabean $\beta$-conglycinin remain unknown. Animal studies have reported that feeding soyabean $\beta$-conglycinin lowered fatty acid synthetic activity and increased the activities of $\beta$-oxidation enzymes such as carnitine palmitoyl transferase and acyl-CoA in the liver, and that faecal excretion of TAG was increased ${ }^{(11)}$. This finding suggested that the concentration of the substrate (NEFA) for TAG synthesis was decreased by consuming soyabean $\beta$-conglycinin. Moriyama et al. ${ }^{(8)}$ reported that soyabean $\beta$-conglycinin could induce fatty acid $\beta$-oxidation, inhibit hepatic fatty acid synthesis and inhibit the absorption of TAG in normal or obese animals. The present study also found that the $\beta$-conglycinin intervention for 12 weeks significantly decreased the concentrations of NEFA in the test groups. In addition, Manzoni et al. ${ }^{(16)}$ confirmed that $\beta$-conglycinin can stimulate LDL degradation in cultured hepatic HepG2 cells and inhibit the expression of LDL receptors.

In conclusion, the results from the present study suggest that $\beta$-conglycinin consumption at levels of 2.3 and $4.6 \mathrm{~g} / \mathrm{d}$ significantly improves serum lipids in hyperlipidaemic menopausal women.

\section{Acknowledgements}

The present study was supported in part by a grant from the National Natural Science Foundation of China (no. 81172653 and 30872115) to Y. Z., the National Natural Science Foundation of China (no. 30872114) to P. W. and the Beijing Natural Science Foundation (no. 7122103) and the National Natural Science Foundation of China (no. 81202193) to D. M.

The authors' responsibilities were as follows: K. T., Y. Z. and P. W. participated in the design of the study. D. M., M. J. and Y. W. performed the randomised controlled trial and the statistical analysis. All authors read and approved the final manuscript.

The authors declare that there are no financial and personal relationships with other people or organisations that could inappropriately influence the present study.

\section{References}

1. Anderson JW, Johnstone BM \& Cook-Newell ME (1995) Meta-analysis of the effects of soy protein intake on serum lipids. $N$ Engl J Med 333, 276-282.

2. Adams MR, Golden DL, Franke AA, et al. (2004) Dietary soy beta-conglycinin (7S globulin) inhibits atherosclerosis in mice. J Nutr 134, 511-516.

3. Anonymous (1999) Food labeling: health claims; soy protein and coronary heart disease. Food and Drug Administration, HHS. Final rule. Fed Regist 64, 57700-57733.

4. Sacks FM, Lichtenstein A, Van Hom L, et al. (2006) Soy protein, isoflavones, and cardiovascular health: an American Heart Association Science Advisory for professionals from the Nutrition Committee. Circulation 113, 1034-1044.

5. Aoyama T, Kohno M, Saito T, et al. (2001) Reduction by phytate-reduced soybean beta-conglycinin of plasma triglyceride level of young and adult rats. Biosci Biotechnol Biochem 65, 1071-1075.

6. Duranti M, Lovati MR, Dani V, et al. (2004) The alpha' subunit from soybean $7 \mathrm{~S}$ globulin lowers plasma lipids and upregulates liver beta-VLDL receptors in rats fed a hypercholesterolemic diet. J Nutr 134, 1334-1339.

7. Sirtori CR, Even R \& Lovati MR (1993) Soybean protein diet and plasma cholesterol: from therapy to molecular mechanisms. Ann N Y Acad Sci 676, 188-201.

8. Moriyama T, Kishimoto K, Nagai K, et al. (2004) Soybean beta-conglycinin diet suppresses serum triglyceride levels in normal and genetically obese mice by induction of betaoxidation, downregulation of fatty acid synthase, and inhibition of triglyceride absorption. Biosci Biotechnol Biochem 68, 352-359.

9. Kohno M, Hirotsuka M, Kito M, et al. (2006) Decreases in serum triacylglycerol and visceral fat mediated by dietary soybean beta-conglycinin. J Atheroscler Thromb $\mathbf{1 3}$, $247-255$.

10. Gaddi A, Ciarrocchi A, Matteucci A, et al. (1991) Dietary treatment for familial hypercholesterolemia - differential effects of dietary soy protein according to the apolipoprotein E phenotypes. Am J Clin Nutr 53, 1191-1196.

11. Fukui K, Kojima M, Tachibana N, et al. (2004) Effects of soybean beta-conglycinin on hepatic lipid metabolism and fecal lipid excretion in normal adult rats. Biosci Biotechnol Biochem 68, 1153-1155.

12. Ohara S, Matsui Y, Tamesada M, et al. (2007) Serum triacylglycerol-lowering effect of soybean beta-conglycinin in mildly hypertriacylglycerolemic individuals. $e-S P E N \mathbf{2}$, $12-16$.

13. Jenkins DJ, Mirrahimi A, Srichaikul K, et al. (2010) Soy protein reduces serum cholesterol by both intrinsic and food displacement mechanisms. J Nutr 140, 2302S-2311S.

14. Mochizuki Y, Maebuchi M, Kohno M, et al. (2009) Changes in lipid metabolism by soy beta-conglycinin-derived peptides in HepG2 cells. J Agric Food Chem 57, 1473-1480.

15. Ministry of Health, Labour and Welfare (2007) The National Health and Nutrition Survey in Japan (in Japanese). Tokyo: Daiich Shuppan Publishing; 2010.

16. Manzoni C, Duranti M, Eberini I, et al. (2003) Subcellular localization of soybean $7 \mathrm{~S}$ globulin in HepG2 cells and LDL receptor up-regulation by its alpha' constituent subunit. J Nutr 133, 2149-2155. 